\title{
A POÉTICA DOS RESÍDUOS EM QUARTO DE DESPEJO: POR UMA DIETÉTICA DA ESCASSEZ ${ }^{1}$
}

\author{
Michelle Cristine Medeiros Jacob (UFRN) \\ Viviany Moura Chaves (UFRN)
}

Resumo: O escritor Roland Barthes já dizia que a literatura é um monumento por excelência, pois através dela pode-se discutir qualquer coisa. Em verdade a literatura traz possibilidades de estudos para compreender fenômenos ligados à condição humana. A obra Quarto de despejo, de Carolina Maria de Jesus, foi utilizada neste estudo como objeto de conhecimento, como corpus de pesquisa. Negra e pobre, Carolina se revela através dos seus diários como uma escritora que enaltece temáticas de caráter social e proibitivo para a época dos anos 60. Nesse sentido, um dos temas mais marcantes e inarredáveis de sua obra é a mazela da fome. Este estudo objetiva compreender o papel da escrita como via para subjetivação e enfrentamento da situação de precariedade alimentar vivenciada pela poetisa. Por meio dos escritos de Carolina, acredita-se que a escrita funciona como mecanismo para produção de uma poética da dignidade no contexto da fome.

Palavras-chave: Literatura; Fome; Carolina Maria de Jesus; Quarto de despejo.

Abstract: The writer Roland Barthes once said that literature is a monument of excellence, because through it you can discuss anything. In fact, the literature brings studies possibilities to understand phenomena related to the human condition. The book Quarto de despejo, of Carolina Maria de Jesus, was used in this study as an object of knowledge, such as research corpus. Black and poor, Carolina is revealed through their diaries as an african-Brazilian writer exalting themes of social character and prohibitive for the time of year 60. In this sense, one of the most striking and ineligible themes of his work is the hunger illness. This study aims to understand the role of writing as a means of subjectivity and face the situation of food insecurity experienced by the poet. Through written grimy Carolina, it is believed that writing functions as a mechanism for producing a poetry dignity in hunger context.

Keywords: Literature; Hunger; Carolina Maria de Jesus; Quarto de despejo.

1 Título do artigo em inglês: "The poetics of the waste in Quarto de despejo: by dietary of scarcity". 


\section{UM DIÁLOGO ENTRE UMA LITERATURA DAS MARGENS E O REGIME DA ESCASSEZ}

A miséria instaurada, excrementos fétidos entre barracos, a extrema pobreza e um povo condenado por uma mazela intocável - a fome -, são algumas características descritas no cenário vivenciado por Carolina Maria de Jesus em sua obra literária Quarto de despejo: o diário de uma favelada.

O diário causou grande impacto nas camadas populares nos anos 60, visto que, naquela ocasião, pela primeira vez, uma voz marginalizada denunciou a situação de precariedade e desumanização enfrentada pelos moradores da favela do Canindé, o que evidenciou e evidência a realidade de milhares de brasileiros (MEIHY, 1998). Dessa forma, Quarto de Despejo, escrito por uma mulher, negra e catadora de lixo, relata a voz daquele posto à margem contando sua própria história.

O sentido do termo marginal na obra, diz respeito à condição dos sujeitos pertencentes às classes sociais menos favorecidas, aqueles que estão economicamente, sobretudo, às margens dos privilegiados da sociedade (classes abastadas). Na narrativa caroliana, o "marginal" tem origem do humilde, onde a "voz da periferia" ocupa os segmentos literários no interior da obra. A identidade marginal de 
Carolina se constrói a partir da inserção social e cultural da autora que morou numa favela situada às margens do rio Tietê (CORONEL, 2012).

Dessa forma, assim como Carolina Maria de Jesus reciclava lixo para se alimentar, reciclava discursos em sua poética dos resíduos, pois sua literatura é marcada por uma mistura de estilos literários desterritorializados, sendo capaz de ativar uma linha de fuga em relação às literaturas canonizadas (FERNANDEZ, 2008).

Os registros textuais de Carolina Maria de Jesus, a autora da obra, carregam a essência de vida de uma escritora que conviveu com a mazela da fome e utilizou a escrita como uma arma de superação, perante toda a situação de precariedade que vivenciou. A obra é apresentada na forma de diário, o que conduz o leitor a enxergar a realidade em volta de Carolina com os olhos e sentimentos dela, que se subjetiva em sua escrita. Concorda-se com Calligaris (1998) ao pensar que na narrativa biográfica o fato em si não é o que mais importa, mas uma verdade que habita o sujeito de onde provem um modo de narrar. Carolina não apenas traz fatos, ela escolhe o que narrar, como narrar.

O escrito biográfico para o autor tem um forte elemento de criação (literatura): o diário é uma aventura a ser 
inventada. É importante destacar que esta obra trata-se de um diário e, portanto, traz consigo a expressão literária como uma sucessão de fatos ocorridos e vivenciados durante o cotidiano na forma de um registro pessoal. Partindo desse pressuposto, Carolina em seu diário torna-se uma autora/ narradora que, de modo intuitivo, desbrava sua reflexão, sua discussão e seus julgamentos sobre a sua condição de vida e a dos favelados, tornando-se uma porta-voz da classe marginalizada.

Sabe-se que a ficção e a realidade estão inter-relacionadas, e que a literatura, quando preciso, cumpre seu papel como veículo de denúncia social (LIEBIG, 2011). Porém, o diário de Carolina vai além das colocações acerca das iniquidades sociais, trata-se também de uma autobiografia, com o intuito de retratar o seu eu, de afirmar a identidade que ela deseja transparecer. Contudo, há traços de realidade e ficção nos relatos autobiográficos, pois o artista ao se representar decide que imagem pretende transmitir e qual identidade deseja expor (QUERIDO, 2012). Toma-se como exemplo a ação de tirar uma fotografia, no qual Roland Barthes afirma: “Louca ou sensata? A fotografia pode ser uma ou outra: (...) cabe a mim escolher, submeter seu espetáculo ao código das ilusões perfeitas ou afrontar nela o despertar da intratável 
realidade" (1984, p.175). Assim, quando o sujeito sente-se olhado pela objetiva da câmera tudo muda, pois este sujeito fabrica-se instantaneamente e assim decide que imagem deseja passar.

Diante disso, Quarto de despejo é uma obra literária que possibilita incursões sobre temas relacionados a defechos sociais como: a relutância sobre a inserção da mulher negra nos escritos literários, preconceito com gênero, raça e condição socioeconomica, desigualdade social, marginalidade, pobreza, etc. Os escritos da autora buscam por respostas para questionamentos inerentes ao indivíduo e ao coletivo, em meio a reflexões relacionadas à condição humana. Assim, tal obra propicia a compreensão desta condição ocupada pela autora através de sua própria perspectiva. Porém, para a explanação deste artigo será abordado em específico outro tema relevante e que se apresenta permanentemente durante a obra: o flagelo da fome. Nesse sentido, pretende-se trazer compreensões acerca do papel da escrita de Carolina Maria de Jesus como via para subjetivação e enfrentamento da escassez.

\section{O DIÁRIO DE CAROLINA: SUA HISTÓRIA REVELADA}

Carolina Maria de Jesus nasceu na cidade mineira de Sacramento, no triângulo Mineiro, no ano de 1914 - porém, 
ainda há controvérsias quanto à data. Nascida em uma família de negros e mulatos, foi criada pela mãe, Maria Carolina, e pelo avô, Benedito José da Silva, com os quais possuía bons vínculos afetivos (SILVA, 2007).

A mãe da escritora foi uma mulher que também enfrentou preconceitos relacionados à condição de ser uma mulher negra. Assim como Carolina, exerceu a função de lavadeira de roupas para garantir a renda e o sustento do domicílio. Embora casada com um homem que não era o pai biológico de Carolina, assumiu publicamente ter tido uma relação extraconjugal e, com isso, sofreu com atitudes moralistas e discriminatórias dos moradores ao julgarem seus atos. Com o nascimento de Carolina, o marido a abandonou.

Com o desconhecimento afetivo e a ausência da presença paterna, Carolina pareceu compensar esta falta com seu avô materno. Benedito da Silva era um ex-escravo descendente de africanos e costumava contar histórias para a neta (SILVA, 2007). A escritora sempre o referenciava de forma amável, descrevendo-o como: "um preto alto e calmo. Resignado com o soldo da escravidão. Não sabia ler, mas era agradável no falar. Foi o preto mais bonito que já vi até hoje" (JESUS, 1986, p.7).

Desde muito cedo, Carolina teve uma infância difícil e extremamente pobre, trabalhava com a mãe na roça e 
contribuía no serviço pesado de casa. Nesta passagem de sua obra Diário de Bitita (1986), Carolina narra sobre como era o seu trabalho enquanto ainda era uma menina:

Minha mãe cozinhava com lenha. Nós não podíamos comprar, íamos buscá-la no mato. [...] Levávamos um machado. Que suplício andar no mato procurando um pau aqui, outro ali. Quando encontrávamos um pau seco, que alegria! Era como se encontrássemos um filão de ouro. Era aquela andança dentro do mato, das sete ao meio-dia. Eu gostava de ir para comer frutas silvestres - jatobá, pitanga, gabiroba, araticum, maracujá e marmelo-de-cachorro. Não gostava do retorno. Minha mãe me obrigava a carregar um feixe de lenha. Eu era fraca e não suportava o peso. Mas não podia reclamar. Já estava começando a compreender que para viver temos que nos submeter aos caprichos de alguém. Quando não é a mãe, é o esposo ou o patrão. Que dor horrível nas pernas! O peso me comprimia para baixo, como se quisesse introduzir minhas pernas dentro da terra. Quando chegava em casa e jogava o feixe de lenha, que alívio! la sentar para descansar. (1986, p.96-97)

Embora tivesse que trabalhar desde cedo, a escritora foi alfabetizada e estudou até o segundo ano primário, graças a uma instituição espírita. Em 1937, na condição de negra, mulher e pobre, migrou para a cidade de São Paulo em 
busca de melhorias de vida. O motivo de sua saída de Minas Gerais foi devido à impetuosa miséria instalada que abatia os camponeses desafortunados. Após peregrinar no interior das cidades do estado de São Paulo, chegou na capital e logo começou a trabalhar em diversas profissões, desde empregada doméstica até artista de circo. Como doméstica, trabalhou nas casas de algumas famílias. Insatisfeita com o trabalho, Carolina decidiu alçar novos voos e passou a trabalhar como catadora de papel nas ruas paulistas. Com este tipo de trabalho, encontrou mais tempo para cuidar dos filhos, ser doméstica do próprio lar, bem como realizar suas leituras e registros nos diários (MEIHY, 1998).

Moradora da primeira grande favela de São Paulo, mãe solteira de três filhos - José Carlos, João José e Vera Eunice - cada um de pais diferentes, escrevia páginas e páginas no seu diário com o intuito de publicá-lo (QUERIDO, 2012). Mais tarde, a poetisa não imaginava que o diário em que ela escrevia habitualmente iria se transformar em um livro, um fenômeno editorial logo na sua primeira edição.

Depois de várias tentativas frustradas de publicações mal sucedidas, em abril de 1958 um jovem jornalista - Audálio Dantas -, enquanto ia realizar uma reportagem na favela do Canindé sobre a instalação de equipamentos de playground pela prefeitura, conheceu Carolina e, com o consentimento da 
autora, teve acesso aos seus manuscritos (SILVA, 2008). Ocorre que ainda há controvérsias sobre até que ponto os textos de Carolina seguiram sua real originalidade.

Logo no prefácio de Quarto de Despejo, Dantas explica que procurou manter a originalidade do texto da escritora, incluindo também seus erros de grafia. No entanto, segundo o jornalista (co-autor), alguns recortes feitos foram necessários, uma vez que, muitas passagens poderiam vir a ser consideradas perturbadoras para a sociedade da época (FERNANDEZ, 2006).

Durante a etapa de publicação, Audálio Dantas promove uma revisão gramatical e vocabular dos escritos, além de organizálos numa estrutura própria. Nessa etapa, observaram-se três tipos de modificação em relação aos manuscritos: acréscimos, substituições e supressões. No processo de transposição dos diários, houve evidências de que o editor quis compor uma imagem da autora diferente dos seus manuscritos (PERPÉTUA, 2003).

Em agosto de 1960, Quarto de despejo foi publicado proporcionando-lhe prestígio na mídia, reconhecimento e uma situação financeira estável. A obra foi um sucesso absoluto, atingiu cerca de 100 mil exemplares, que foram traduzidos em 13 línguas diferentes, em mais de 40 países (SILVA, 2008; QUERIDO, 2012). 
Carolina teve uma extensa produção literária. Sua trajetória em escritos abrangia um conjunto de textos diversos registrados nas formas de diários, peças teatrais, provérbios, contos, romances, cartas e bilhetes, textos memorialísticos e poemas. As memórias e depoimentos sobre a infância e juventude de Carolina, são relatados, em sua maioria, na obra Diário de Bitita (1986). A narrativa reúne um registro enriquecido de descrições de situações vividas, fatos sobre a família, relatos de temas do cotidiano, e possibilita contemplar marcos cronológicos de sua trajetória de vida, viabilizando ao leitor referências sobre datas fixadas pela própria escritora. Portanto, esta obra é um dos mais importantes registros de memórias da infância e juventude de Carolina. Além do Diário de Bitita como obra memorialística, os textos Sócrates Africano e Minha vida também registram informações sobre sua infância e juventude (SILVA, 2007).

Após o auge de sua carreira como escritora, Carolina caiu no esquecimento do público depois do sucesso de Quarto de despejo. Conseguiu publicar algumas obras como o romance Pedaços de fome e as suas memórias em o Diário de Bitita, porém estas não foram bem sucedidas.

Morreu, em fevereiro de 1977, aos 62 anos, a cinderela do lixo, em condições de pobreza. 


\section{ALIMENTAÇÃO E LITERATURA: A FOME QUE ALIMENTA A ESCRITA}

Na literatura, se o comer foi mencionado amplamente, o não comer também teve sua atenção e relevância. Autores como Carolina Maria de Jesus, Josué de Castro, Graciliano Ramos, João Cabral de Melo Neto, Dostoiévski, Victor Hugo, Kafka, entre outros, desvelaram em suas obras uma das questões mais problematizadoras do mundo e do humano: a fome.

A questão da fome no interior das discussões literárias perpassaram diversas obras da literatura de renome, sendo um tema marcado pela sua dureza, miséria e precariedade. No Brasil a miséria e a falta de alimentos compõem inúmeras páginas de obras renomadas, das quais utilizavam a escrita para evidenciar críticas, hostilidades de uma vida tomada por dificuldades impostas pelo meio, singularidades do homem regionalista, etc (PINTO; MEDEIROS, 2011).

Na década de 30, alguns autores como Raquel de Queiroz em O quinze (1930), Graciliano Ramos em Vidas secas (1938), José Lins do Rego em Menino de engenho (1932), entre outros, abordaram o tema da fome nos chamados "romances nordestinos" ou "romances de 30". Nessa época, essa mazela era tratada como um tabu da civilização, pois se considerava 
um tema delicado, proibido e pouco aconselhável de ser discutido em público (KIFFER, 2009). A publicação das obras foi considerada um marco histórico do regionalismo nordestino.

Mais tarde, em meados dos anos 60, Carolina Maria de Jesus mostra em seus escritos dos cadernos encardidos uma visão de dentro da favela, a realidade de uma condição de vida subumana onde tem a fome como personagem trágica e inarredável. "A fome aparece no texto com uma frequência irritante [...] tão grande e tão marcante que adquire cor [...]" (2005, p.3). Na obra, Carolina utiliza a escrita como um fator protetor perante a vulnerabilidade social instalada ao seu redor, usando-a para registrar, de acordo com sua perspectiva, as constantes lutas em busca da sobrevivência.

Dessa forma, observa-se uma difusão dos escritos literários que atentam para o fenômeno da fome. A literatura como expressão artística tem cumprido seu papel de disseminador do conhecimento humanístico, do ato de criação e da produção artística. Assim, encontra-se no diálogo da literatura com esta temática, uma maneira de despertar no mundo inquietações do imaginário, (re)pensando sobre como compreender os aspectos singulares daqueles que passam por privação alimentar. 
Alguns estudos se propõem a pensar em questões sócioculturais da alimentação humana pela via da literatura, compreendendo-a como objeto de conhecimento (PEREIRA FILHO, 2010; SANTOS, SOUZA, 2011). Por exemplo, Medeiros em um estudo sobre uma culinária indócil, utilizou a obra Em busca do tempo perdido, do francês Marcel Proust, como corpus de pesquisa. Neste estudo, foi possível demarcar e problematizar o conceito de culinária - compreendendo-a como um sistema cultural alimentar -, caracterizando-a como indócil a partir de cinco pontos elencados na obra (MEDEIROS, 2014). Desse modo, a autora, citando Roland Barthes, defende a afirmação de que o discurso literário parte do imaginário, do devir, da subjetividade, da incerteza, elementos indissociáveis do humano e que, portanto, a literatura é compreendida como criação (BARTHES, 2004). Além disso, deve ser considerado que a literatura é mais do que uma escrita ficcional e imaginativa, ou uma "escrita bonita". Por meio dela permite-se ir para além de um enunciado maquiado por uma precaução que teme o incerto, o involuntário, a criação, a literatura é uma enunciação que expõe dobras que auxiliam na compreensão do humano (MEDEIROS, 2014).

Para Barthes a literatura é como uma "trapaça salutar, uma esquiva, um logro magnífico", pois através dela a língua 
está fora do poder - o discurso da arrogância - permitindo que as forças da liberdade se façam presentes na literatura, assumindo assim, liberdade de escrita (2007, p.16). O autor ainda afirma que caso as disciplinas do ensino acabassem, apenas uma deveria ser salva: a literatura, pois ela é um monumento transdisciplinar por excelência, ou seja, todas as ciências estão presentes nesse monumento literário.

Portanto, a literatura se torna um meio adicional e potente para compreender os questionamentos profundos da condição humana, uma vez que possibilita um pensar voltado para a subjetividade do indivíduo ou da coletividade, rompendo assim com o pensamento pragmático e objetivo ao qual frequentemente os estudos das ditas Ciências duras (exatas, tecnológicas, biomédicas) se propõem.

Dessa forma, trabalhar a questão da fome através do viés literário é de fato uma forma viável de método para estudos acadêmicos, pois permite (1) que o pesquisador reflita sobre a problemática em questão em seus diferentes enfoques e assim realize correlações com temáticas inerentes ao contexto da atualidade; e (2) que o artista seja o mediador dessa construção do conhecimento, visto que ele expõe o universo que existe dentro de si, não se comprometendo apenas em mostrar as denúncias sociais, mas dialogando 
também com um imaginário coletivo que permeia a questão. Então, a literatura é importante, pois excita a imaginação, proporcionando um deslocamento do imaginário para outras dimensões, fala sobre o mundo e, sobretudo, atinge com a condição do sujeito.

\section{A poética dos resíduos da cinderela do lixo}

A escrita na obra e vida de Carolina foi uma peça fundamental para enfrentar os desafios do seu cotidiano. Negra, pobre, catadora de lixo e semi-analfabeta, são algumas características da escritora, que, com a publicação de sua obra, pôde revelar ao mundo o verdadeiro cenário de seu mundo.

A poetisa do lixo encontrou na escrita meios para subjetivarse e para trazer à tona sua condição de vida, visto que seus registros expõem as denúncias que ela mesma concebe sobre a miséria no Canindé. Sendo assim, Carolina sabe que tem em suas mãos uma arma valiosa: a escrita. Por não se conformar com suas condições precárias, utiliza a escrita como uma arma, a qual a possibilita lutar, através do uso da palavra, contra a realidade dura e amarga da favela (SANTOS; SOUZA, 2011). Como a própria autora expressa: as "palavras ferem mais do que espada. E as feridas são incicatrizáveis" (2005, p.43). Suas palavras são como armas, ferem, mas também trazem conforto sobre a fome que a assola. 
A obra de Carolina nos mostra o que significa para ela registrar o que vivencia. [...] A escrita é usada como arma, [...] serve de conforto à fome, de alimento que lhe preenche a alma. Sua alma é de poeta e, como ela própria nos diz, o poeta enfrenta a morte quando vê o seu povo oprimido. (BENEVUTO, 2006, p.25)

Carolina torna-se diferente dos outros favelados à medida que escreve. A escrita a faz se sentir mais digna perante os demais moradores. Segundo Benevuto (2006), Carolina revela em sua poesia a experiência trapeira de sua vida, que se distancia do prosaico que se encontra e tenta elevar-se ao sublime. Assim como cita Benjamin (1994), todo artista tem um pouco de trapeiro, de mendigo, catador de lixo. Para ele, o artista lida com o prosaico, no qual desce "das alturas" e precisa vestir-se do trapeiro, porém no caso de Carolina, ela é a própria trapeira e a escrita parece ser o veículo que encontra para chegar ao sublime.

Além disso, a tentativa de escrever "literariamente" Ihe serve como uma linha de fuga, ativada toda vez que sente vontade de devanear, fugir do espaço que não considera próprio para sua existência. Desse modo, percebe-se o impasse da obra de Carolina, quando o insistente desejo de falar sobre o "belo", se depara com sua narrativa desprovida de beleza sobre a realidade. A própria autora reconhece esse 
impasse: "Como é horrível ouvir um pobre lamentando-se. A voz do pobre não tem poesia" (2005, p.74). Para ela, a poesia deveria nascer de uma beleza higiênica, visto que a matéria da sua narrativa não é bela, e o seu relato não é "poético" no sentido mais convencional do termo, mas no registro da poiésis, palavra de origem grega, remete à criação, ação, confecção, fabricação (FERNANDEZ, 2008).

É importante ressaltar também que outros artistas utilizaram a escrita a partir de fragmentos de vida, resíduos, por assim dizer, para produzir obra de arte. Por exemplo, Antonin Artaud. Depois de diagnosticado por Lacan de que não escreveria mais uma linha, deixa uma obra imensa como forma de se reposicionar no mundo. Inventou vida pela escrita. As previsões de Lacan foram completamente desmentidas: dos 26 volumes que compõem as obras completas de Artaud, somente oito foram escritos antes de 1937, isto é, antes que iniciasse o calvário das internações (TEIXEIRA, 1999).

\section{A fome em sua personificação}

A fome presente na obra na obra, sem dúvidas, é um dos maiores entraves que Carolina enfrentou para garantir a sua sobrevivência e a dos seus filhos. Os registros no seu diário mostram a luta cotidiana da favelada contra seu maior vilão: 
a fome. A fome aparece nos seus escritos com uma presença marcante e frequente, despertando involuntariamente a tristeza, o sofrimento, o medo e até mesmo o desejo de suicídio, como foi discutido anteriormente.

Durante as passagens no diário a fome toma corpo, podendo ser considerada como uma personagem trágica e inarredável. Segundo Audálio Dantas, a fome é tão grande e marcante que adquire cor na narrativa tragicamente poética de Carolina. Para ela, a cor da fome era "amarela", uma vez que, na sua busca diária pela sobrevivência, em meio ao lixo, ela percebeu que quando a fome atingia seu limite suportável, todas as coisas que estavam perante seus olhos ficavam amarelas. Carolina também relaciona a fome como uma "professora", uma "juíza”, assim enfatizando que só aqueles que passam fome sabem valorizar a vida, devido às dificuldades que foram aprendidas na sua presença (JESUS, 2005).

De forma semelhante, na obra Agonia da fome, de Maria do Carmo Freitas, a fome também é tratada como uma personagem em várias passagens. Os moradores do bairro de Péla, localizado em Salvador - Bahia, experimentam em seu dia-a-dia conviver com a mazela da fome. Para eles "a fome é um beco escuro, uma criatura horrível, um 
espírito, um demônio, um vento, uma fera, uma coisa que nem droga nesse inferno que é o bairro" (2003, p.54). Em outra passagem, a fome é conhecida como a coisa que "produz sensações de 'arrepiar quando a gente sente que ela (a fome) vai chegar [...], vai arrancar as carnes do corpo'” (2003, p.46). O fenômeno da fome produz diversos sentidos e efeitos, na forma de metáforas, que trazem uma dimensão simbólica desse fenômeno, assim, as metáforas relacionadas à mazela possuem muitas moradas no corpo: o peito que dói, a cabeça que endoidece, as pernas que não querem mais andar (FREITAS, 2002).

Ao mesmo tempo, pode ser observado que o homem faminto, miserável e mundano tenta compreender a sua fome, a revelando como uma "figuração", não apenas ao acúmulo de sensações físicas, mas, antes, às sensações vividas pelos indivíduos, causando signos profundos no eu dos sujeitos (FREITAS, 2002). O sentido das figurações dadas pelos famintos, na forma de imagem, diz respeito ao esforço de dar corpo à fome como uma forma de decifração do fenômeno para enfrentá-lo. Nesse sentido, as imagens são as mediações entre o homem e o mundo e emitem a representação de algo. Por exemplo, são as imagens que tem a finalidade de representar o mundo para o homem, 
pois este mundo não lhe é acessível de imediato (FLUSSER, 1985). O mundo, neste caso, pode ser comparado com a fome vivenciada em Quarto de despejo, um imaginário que mediante um conjunto de cenas, se torna possível estruturála, encorporá-la, dar-lhe um corpo para fazê-la próxima à realidade, e assim, enfrentando-a.

O fenômeno interpretativo da fome não pode ser compreendido sob uma linguagem expressa do ponto de vista das necessidades nutricionais do organismo, esta interpretação só pode ser decifrada através do idioma dos sentidos, no qual os sentidos da fome produzem signos por parte dos atores sociais. Estes significados da fome dão lugar à compreensão de uma identidade faminta (FREITAS, 2002).

Portanto, percebe-se a importância dos sujeitos atribuirem um corpo, uma forma ou até mesmo um nome a fenômenos que são intocáveis, neste caso, o fenômeno da fome. Isto acontece pelo fato de que nomear algo que se mostra desfigurado é um modo de fazer ver uma verdade que existe, mas que não possui um corpo próprio para ser confrontado diretamente. Por isso, observa-se que tanto em estudos como na obra, os sujeitos tendem a trazer suas interpretações e compreensões sobre a fome em figurações, para que se crie uma aproximação a partir da sua observação e interpretação sobre este fenômeno. 


\section{Animalização em quarto do despejo}

A abordagem do tema da fome na literatura, por vezes, é tratada de forma dura. A poesia $O$ bicho, de Manuel Bandeira (1986), mostra a incoerência percebida por ele, ao igualar o homem com um animal. Isto porque ambos se alimentam de resíduos e despejos, como vemos no seguinte trecho: "Vi ontem um bicho, na imundície do pátio, catando comida entre os detritos [...] O bicho não era um cão, não era um gato, não era um rato. O bicho, meu Deus, era um homem". Desse modo, em situações de extrema precariedade alimentar, o que diferencia o homem dos animais?

Em Quarto de despejo, Carolina traz relatos dessa natureza, no qual mostra a condição animalizada e bestializada dos favelados:

Os favelados aos poucos estão convencendo-se que para viver precisam imitar os corvos. (2005, p.37)

Não mais se vê os corvos voando as margens do rio, perto dos lixos. Os homens desempregados substituíram os corvos. (2005, p.48).

O motorista e o seu ajudante jogam umas latas. É linguiça enlatada. [...] E quando apodrecem jogam para os corvos e os infelizes favelados. (2005, p.29)

Os animais quem Ihes alimenta é a natureza. [...] Eu penso isto, porque quando eu não tenho nada para comer, invejo os animais. (2005, p.55) 
As analogias realizadas por Carolina mostram a posição em que ela se enxergava enquanto pessoa, alguém que era inferior, menosprezada dentro do contexto da sociedade em que vivia. O lugar dos animais era às margens do rio Tietê, espaço este que deveria ser dividido também com os humanos. Assim, esta associação remetia ao sistema econômico capitalista que, desempenhando um papel de organização, coloca os homens na condição de animais. O uso da animalização do homem na obra, tanto anuncia a capacidade de um discurso capaz de ativar uma linha de fuga em relação às literaturas canonizadas, como também denuncia o desencadeamento da animalização do ser humano, assumindo assim, de um lado um pretenso progresso social a partir destes novos elementos de linguagem, e de outro uma regressão civilizacional (FERNANDEZ, 2006).

Deleuze e Guattari (1995) aplicaram o devir das obras literárias nos seus estudos. Para ambos, a escrita poderia expressar um devir na medida em que venha a ser "uma revelação de algo que atravessa o homem, os afetos marcam as passagens dos devires". Nesse sentido, Fernandez (2006) utiliza a expressão devir-fome - como também devir animal - dentro do contexto da obra de Carolina, e explica que o devir animal é próprio da linguagem de resíduos desterritorializados, que neste caso, emite a percepção de um corvo, desvelando que o 
homem vive sob as mesmas condições dos corvos, sendo esta condição existencial um produto do capistalismo que gera fome e, consequentemente, desumanidade. Por isso, justamente nos registros das misérias humanas uma nova linguagem pode ser processada.

Diante disso, por meio de Quarto de despejo, Carolina Maria de Jesus apresenta uma maneira adicional para discutir o fenômeno da fome, utilizando a literatura como objeto de conhecimento para tratar elementos subjetivos que compõem essa temática e que vão além das descrições epidemiológicas que sustentam os diagnósticos convencionais e biomédicos em torno do problema da fome no país.

A escrita funcionou para a autora como um mecanismo para produção de uma poética da dignidade, no contexto da fome como uma iniquidade social. Carolina deixa claro na sua escrita a necessidade de expressar suas interpretações e significados que atribui à fome, considerando-a como uma manifestação de personalidade que possui um corpo real. Animaliza-se o homem - comparando-o com animais -, demonstrando que não existe diferença entre ambos, afinal os restos de comidas servem tanto para homens como para urubus. Carolina utiliza a escrita como uma arma de potência, encontrando nela algumas possibilidades de vida: (1) um meio para se libertar do ambiente 
sujo em que vivia; (2) o caminho para se inserir em um mundo que a rejeitava como lixo; (3) uma arma de denúncia social.

\section{REFERÊNCIAS}

BANDEIRA, Manuel (1986). O bicho. Rio de Janeiro: Nova Aguilar. BARTHES, Roland (1984). A câmara clara. Rio de Janeiro, Nova Fronteira. (2004). O rumor da língua. São Paulo: Martins Fontes. (2007) Aula. Tradução de Leyla Perrone-Moisés. São Paulo: Cultrix.

BENEVENUTO, Silvana José (2006). Quarto de despejo: A escrita como arma e conforto à fome. Revista eletrônica Baleia na rede, [S.I.], 1, (3).

BENJAMIN, Walter (1994). Obras escolhidas III: Charles Baudelaire um lírico no auge do capitalismo. 3.ed. São Paulo, Brasiliense.

CALLIGARIS, Contardo (1998). Verdades de autobiografias e diários íntimos. Revista Estudos Históricos, 11(21), p.43-58.

CORONEL, Luciana Paiva (2010). Da margem para o centro: a representação do negro em Quarto de despejo, de Carolina Maria de Jesus. In: X Encontro Estadual de História. O Brasil no Sul: cruzando fronteiras entre o regional e o nacional. Santa Maria: RS.

DANTAS, Audálio (2005). Prefácio. In: JESUS, Carolina Maria de. Quarto de despejo: diário de uma favelada. 8.ed. São Paulo.

DELEUZE, Gilles; GUATTARI, Félix (1995). Mil Platôs: capitalismo e esquizofrenia Vol.1. Rio de Janeiro: Editora 34.

FERNANDEZ, Raffaella Andréa (2006). Cartografando uma Literatura Menor: a Poética dos Resíduos de Carolina Maria De Jesus. Revista Patrimônio e Memória. São Paulo: UNESP, 2(1), p.201.

(2008). Percursos de uma poética de resíduos na obra de Carolina Maria de Jesus. Revista Itinerários, Araraquara, 27, p.125-146.

FLUSSER, Vilém (1985). Filosofia da Caixa Preta. São Paulo: Editora HUCITEC. 
FREITAS, Maria do Carmo (2003). Agonia da fome [e-book]. Rio de janeiro: Editora FIOCRUZ: Salvador: EDUFBA. (2002). Uma abordagem fenomenológica da fome. Revista de Nutrição, 15, (1), p.53-69.

JESUS, Carolina Maria de (1986). Diário de Bitita. Rio de Janeiro: Nova Fronteira.

(2005). Quarto de despejo: diário de uma favelada. 8.ed. São Paulo.

KIFFER, Ana Paula (2009). Graciliano Ramos e Josué de Castro: um debate acerca da fome no Brasil. Via Atlântica, Rio de Janeiro.

LIEBIG, Sueli Meira. Redescobrindo Carolina Maria de Jesus, cidadã do mundo. Anais do XIV Seminário Nacional Mulher e Literatura / V Seminário Internacional Mulher e Literatura. In http://www.telunb.com. br/mulhereliteratura/anais/wp-content/uploads/2012/01/sueli_meira. pdf Acesso em 04.Ago.2017.

MEDEIROS, Michelle (2014). Marcel Proust para além das madeleines. Uma culinária indócil. 252f. Tese (Doutorado em Ciências Sociais) Universidade Federal do Rio Grande do Norte, Natal.

MEIHY, José Carlos Sebe Bom (1998). Carolina Maria de Jesus: emblema do silêncio. Revista USP. São Paulo, 37, p.82-91.

PEREIRA FILHO, Waldemar Rodrigues (2010). A fome: ânsia ou carência. Uma Leitura das obras de Rodolfo Teófilo e Knut Hamsun. Anais do seta, [S.1.], 4.

PERPÉTUA, Elzira Divina (2003). Aquém do Quarto de despejo: a palavra de Carolina Maria de Jesus nos manuscritos de seu diário. Estudos de Literatura Brasileira Contemporânea, (22), Brasília, p.63-83.

PINTO, Vera Lucia; MEDEIROS, Michelle (2011). Literatura e alimentação: delicatéssen na formação em saúde. Natal: Editora da UFRN.

QUERIDO, Alessandra Matias (2012). Autobiografia e autorretrato: cores e dores de Carolina Maria de Jesus e de Frida Kahlo. Revista Estudos Feministas, Florianópolis, 20(3), p.384. 
SANTOS, Maricélia Nunesdos; SOUZA, Wagner de (2011). Quarto de despejo - Manifestação do discurso feminino na literatura brasileira, Revista Travessias, 5(2).

SILVA, José Carlos Gomes da (2008). História de vida, produção literária e trajetórias urbanas da escritora negra Carolina Maria de Jesus. In: SEIXAS, Jacy; CERASOLI, Josiane (org). UFU 30 Anos. Tropeçando Universos. Uberlândia, EDUFU.

(2007). Memórias da infância e juventude em Carolina Maria de Jesus (1914-1977). Revista de Ciências Sociais ponto-e-vírgula, São Paulo, 2, p.97-112.

TEIXEIRA, Ana (1999). O teatro da cura cruel. Revista Interface: Comunicação, Saúde, Educação, São Paulo, 3(5), p.187-192.

Michelle Cristine Medeiros Jacob é Doutora em Ciências Sociais pelo Programa de Pós Graduação em Ciências Sociais da Universidade Federal do Rio Grande do Norte (UFRN), onde também atua como professora do departamento de Nutrição. É mestre em Ciências Sociais e graduada em Nutrição pela mesma instituição. Guarda interesse pelos seguintes temas: alimentação e literatura, alimentação e cultura, pesquisa qualitativa em Nutrição. E-mail: michellejacob@outlook.com.

Viviany Moura Chaves é Mestranda em Ciências Sociais pelo Programa de Pós Graduação em Ciências Sociais da Universidade Federal do Rio Grande do Norte (UFRN). Graduada em Nutrição pela Universidade Federal de Campina Grande (UFCG). Guarda interesse pelos seguintes temas: alimentação sob a perspectiva da literatura, cultura e mídia. E-mail: vivianymourachaves@hotmail.com. 